\title{
The Need for Advancement in the Conceptualization of Cultural Competence
}

\author{
Joseph S. Gallegos \\ Cherie Tindall \\ Sheila A. Gallegos
}

\begin{abstract}
The concept of cultural competence has become ubiquitous in human services language and settings. Though the literature from various disciplines is replete with discussions on the topic, there still exists much disagreement regarding the definition of cultural competence as well as how to operationalize, test, and apply concepts related to cultural competence in social service settings. A related issue stems from debate regarding whether cultural competence is a theory, model, paradigm, framework, or perspective. Though cultural competence has been referred to as a theory by some scholars from different disciplines (e.g., Lum, 2005; Blue, Thiedke, Chessman, Kern, \& Keller, 2005; Wu \& Martinez, 2006), there is still disagreement about whether the concepts related to cultural competence actually meet the criteria for a theory and, consequently, whether they can be used to generate hypotheses and allow for independent observations that can be used to continue building theory, conduct empirical research, and provide evidenced-based practice implications. The authors join in this theory debate through an analysis of the elements of theory and conclude that it has better fit with the definition of social perspective than it does social theory.
\end{abstract}

Keywords: Culture, competence, theory

The term "cultural competence" has become ubiquitous in human services language and in human service settings. The concept appeared first in social work literature (Gallegos, 1982; Green, 1982) as well as in counseling psychology literature (Pedersen \& Marsell, 1982; Sue, Bernier, Durran, Feinberg, Pedersen, Smith, \& VasquezNuttall, 1982). A decade later a number of articles calling for cultural competence in nursing and education were published, and, most recently, similar articles appeared in the medical education literature (Suh, 2004; Bigby, 2003.) As early as the 1980's, following the social directions initiated by the civil rights movements, federal mandates and, in turn, local governments made the inclusion of cultural competence objectives a funding requirement for service programs. From coast to coast, from Portland to Philadelphia, laws have been enacted requiring public agencies to comply with cultural competence standards (Multnomah County, 2005; and Adams, 2005.)

Today organizations and social work programs commonly espouse cultural competence in their mission statements. The National Association of Social Workers (NASW) provides an operational definition (2001) which is a key element of a theory suggesting measurability and suggesting quantitative accountability is attainable. The authors consider the concept of cultural competence against criteria that establishes a concept as a theory and conclude that it is not a theory and that cultural competence is

Joseph Gallegos Ph.D. is the Director of the Social Work Program at the University of Portland. Cherie Tindall B.S. is a Master's Degree candidate in the Cross Cultural Studies Program at the University of Houston at Clear-Lake. Sheila Gallegos M.A. is a Research Associate with Western Research Associates.

Copyright (C) 2008 Advances in Social Work Vol. 9 No. 1 (Spring 2008), 51-62. 
better thought of as a value-based perspective. This conclusion is important with respect to our expectations of social work students and practitioners in setting outcome goals and objectives. This determination is also important because, if we, as a profession, continue to promote a valued-professional goal as if it were a hard scientifically-measurable concept by which we can hold individuals and organizations accountable, and do not acknowledge the malleable nature of the concept, then we continue to allow the profession to be vulnerable to criticism of conservative and libertarian views.

\section{CULTURAL COMPETENCE}

There are several iterations of cultural competence as described by different authors with each striving to describe the concept, such as: Ethnic Competence (Gallegos, 1982; Green,1995), Cultural Awareness (Winkleman, 2005), with the majority of authors eventually converging on the term "Cultural Competence" (Cross, Bazron, Dennis, \& Issacs, 1989; Lum, 2005; Weaver, 2005).

Additional areas of contribution to the body of knowledge on the subject come from other professional literature in helping fields such as psychology, education, and the medical field (Bigby 2003; Purnell \& Paulanka, 2003). Most recent contributions call for progressing beyond cultural competence into "transnational competence" (Koehn \& Swick, 2006). The tremendous volume of literature alluded to earlier on the topic of cultural competence illustrates the importance of the concept as a tool for effective communication, intervention, and outcomes in the multicultural environment pervasive in the helping professions. (Klienman \& Benson, 2006; Williams, 2006). Table 1 contrasts efforts to conceptualize cultural competence in social work and health care. One can see immediately an eclectic array of theories and constructs used to formulate the various conceptualizations of cultural competence. In education literature addressing cultural competence, one would see terms such as multi-culturalism, diversity, poverty, and social justice (Inside Higher Education, 2006).

\section{SOCIAL WORK ACCREDITATION STANDARDS}

Supporting the promotion of cultural competence in social work practice, the Council on Social Work Education (CSWE) requires all accredited programs to incorporate standards regarding diversity, populations at risk, and social justice (CSWE, 2006, Fifth Ed., Education Policies, Standards 4.1 and 4.2) which seem to have encouraged many, if not most, schools of social work to incorporate the term "cultural competence" in their mission statements if not in their learning objectives. The NASW, which sets the standards of practice, incorporates similar practice objectives in its code of ethics and offers an operational definition of cultural competence. 
Table 1. Matrix of Cultural Competence Theories/Models/Perspectives

\begin{tabular}{|c|c|c|c|c|}
\hline Theory/Model/Author & $\begin{array}{l}\text { Major Components/ Defining Terms \& } \\
\text { Process Steps }\end{array}$ & Fields of Focus & $\begin{array}{l}\text { Major Distinctions/ } \\
\text { Based Upon }\end{array}$ & Sources \\
\hline $\begin{array}{l}\text { Cultural Competence, } \\
\text { Practice Stages, Client } \\
\text { Intersectional Systems, \& } \\
\text { Case Studies Model; } \\
\text { Doman Lum \& others }\end{array}$ & $\begin{array}{l}\text { cultural competence, cultural awareness, } \\
\text { knowledge acquisition, skill development, } \\
\text { inductive learning; } \\
\text { mastery of particular set(s) of knowledge, skill, } \\
\text { policies, \& programs used to address cultural } \\
\text { needs of individuals, families, groups, \& } \\
\text { communities; social patterns, social work } \\
\text { values, honor \& respect the cultural values } \\
\text { w/in the larger context, implications of social } \\
\text { class, and ethnic \& social stratification }\end{array}$ & Social Work & $\begin{array}{l}\text { Cultural Competence } \\
\text { Model; } \\
\text { Practice Stages; } \\
\text { Main theory based } \\
\text { upon a Systems-theory } \\
\text { Approach; } \\
\text { Five-stage } \\
\text { continuum that } \\
\text { constitutes a } \\
\text { system (Lum } \\
\text { 1999, pg. 7) } \\
\end{array}$ & $\begin{array}{l}\text { Terry L. Cross, et.al. } \\
\text { (1989); } \\
\text { Lum, Doman Culturally-competent } \\
\text { practice: A framework for growth } \\
\text { and action (1999) }\end{array}$ \\
\hline $\begin{array}{l}\text { Purnell Model for Cultural } \\
\text { Competence (Purnell \& } \\
\text { Paulanka, 2003) }\end{array}$ & $\begin{array}{l}\text { Cultural competence scale, awareness, } 12 \\
\text { domains: } \\
\text { overview/heritage, } \\
\text { communication, } \\
\text { family roles and organization, } \\
\text { workforce issues, } \\
\text { biocultural ecology, } \\
\text { high-risk behaviors, } \\
\text { nutrition, } \\
\text { pregnancy and childbearing practices, } \\
\text { death rituals, } \\
\text { spirituality, } \\
\text { health-care practice, } \\
\text { health-care practitioner concepts }\end{array}$ & $\begin{array}{l}\text { Health care: } \\
\text { practice, } \\
\text { administration, } \\
\text { education, \& } \\
\text { research }\end{array}$ & $\begin{array}{l}\text { A conceptualization } \\
\text { based on multiple } \\
\text { theories and a } \\
\text { research base gained } \\
\text { from organizational, } \\
\text { administrative, } \\
\text { communication, and } \\
\text { family development } \\
\text { theories as well as } \\
\text { anthropology, } \\
\text { sociology, psychology, } \\
\text { anatomy and } \\
\text { physiology, biology, } \\
\text { ecology, nutrition, } \\
\text { pharmacology, religion, } \\
\text { history, economics, } \\
\text { political science, and } \\
\text { linguistics. }\end{array}$ & $\begin{array}{l}\text { Campinha-Bacote, J. (1994). The } \\
\text { process of cultural competence, in } \\
\text { the delivery of health-care services: } \\
\text { A culturally-competent model of care } \\
\text { (3rd ed.); } \\
\text { Hage, J. (1972). Techniques and } \\
\begin{array}{l}\text { problems of theory construction in } \\
\text { sociology; }\end{array} \\
\text { Purnell L, \& Paulanka, B. (2003). } \\
\begin{array}{l}\text { Transcultual health care: A } \\
\text { culturally-competent approach. }\end{array}\end{array}$ \\
\hline
\end{tabular}


NASW Standards for Cultural Competence in Social Work Practice

Prepared by the NASW National Committee on Racial and Ethnic Diversity Approved by the NASW Board of Directors June 23, 2001

\section{CULTURAL COMPETENCE}

Cultural competence refers to the process by which individuals and systems respond respectfully and effectively to people of all cultures, languages, classes, races, ethnic backgrounds, religions, and other diversity factors in a manner that recognizes, affirms, and values the worth of individuals, families, and communities and protects and preserves the dignity of each.

Cultural competence is a set of congruent behaviors, attitudes, and policies that come together in a system or agency or among professionals and enables the system, agency, or professionals to work effectively in cross-cultural situations.

Operationally defined, cultural competence is the integration and transformation of knowledge about individuals and groups of people into specific standards, policies, practices, and attitudes used in appropriate cultural settings to increase the quality of services, thereby producing better outcomes (Davis \& Donald, 1997). Competence in cross-cultural functioning means learning new patterns of behavior and effectively applying them in appropriate settings.

Gallegos (1982) provided one of the first conceptualizations of ethnic competence as "a set of procedures and activities to be used in acquiring culturally-relevant insights into the problems of minority clients and the means of applying such insights to the development of intervention strategies that are culturally appropriate for these clients." (p. 4). This kind of sophisticated cultural competence does not come naturally to any social worker and requires a high level of professionalism and knowledge.

There are five essential elements that contribute to a system's ability to become more culturally competent. The system should (1) value diversity, (2) have the capacity for cultural self-assessment, (3) be conscious of the dynamics inherent when cultures interact, (4) institutionalize cultural knowledge, and (5) develop programs and services that reflect an understanding of diversity between and within cultures. These five elements must be manifested at every level of the service-delivery system. They should be reflected in attitudes, structures, policies, and services.

\section{CULTURAL COMPETENCE AS FOUNDATION THEORY IN HUMAN BEHAVIOR AND THE SOCIAL ENVIRONMENT (HBSE)}

Theoretical content most germane to social work is found in HBSE courses. The CSWE stipulates the following standard of educational policy with regard to HBSE: 


\subsection{Human Behavior and the Social Environment}

Social work education programs provide content on the reciprocal relationships between human behavior and social environments. Content includes empiricallybased theories and knowledge that focus on the interactions between and among individuals, groups, societies, and economic systems. It includes: 1) theories and knowledge of biological, sociological, cultural, psychological, and spiritual development across the life span; 2) the range of social systems in which people live (individual, family, group, organizational, and community; 3) and the ways social systems promote or deter people in maintaining or achieving health and well-being.

In a review of five popular HBSE text books, the authors found that Elizabeth D. Hutchinson [Dimensions of human behavior: Person and environment (1999)] includes a short discussion on theory in general and how it relates to study and research. She also includes a chapter on "theoretical perspectives on human behavior" in which she describes different theoretical approaches used in social work settings, utilizing case studies throughout the book to elucidate how each of the approaches may be used in various HBSE situations. D. Lum and D.W. Sue \& D. Sue are leading authors in cultural competency literature that are referenced in the Works Cited section of the Hutchinson text and, although the importance of appreciating different cultural needs is stressed, the term “cultural competence” is not used.

In the HBSE text book by José B. Ashford, Craig Winston LeCroy, and Kathy L. Lortie, Human behavior in the social environment: A multidimensional perspective (2006), in chapter one of the text, "A multidimensional framework," the authors include a section that discusses "cultural competence, globalization, and our diverse society." This is a short section that briefly addresses the significance of cultural competence and cultural diversity as related to the globalization of cultures but does not include any references to any particular authors on the topic. The text includes sections titled "Multicultural and gender considerations" within each of the chapters concerned with various stages of child development, family considerations, and community systems, but these are more application-oriented rather than theoretical.

The text by John F. Longres, Human behavior in the social environment (2000), introduces and briefly describes the term "cultural competence" in the first chapter of the text during discussion of social theories, and, herein, the author references James W. Green's work titled Cultural awareness in the human services: A multiethnic approach (1982). As with the other HBSE texts noted above, this text includes multicultural considerations as applicable to each topic of discussion or case study throughout the work but presents little exploration of cultural competence as a theory.

Another popular HBSE is the text by Charles H. Zastrow and Karen K. KirstAshman [Understanding human behavior in the social environment (2004)] which is the most in depth of the HBSE texts reviewed as far as the discussion of cultural competence is concerned, but even this consisted of only two and a half pages of information on 
culturally-competent practice. Cultural competence is defined in the text as the need to follow the "ten standards for cultural competence in social work practice" as defined by NASW (2001). The work then moves on to discuss application of the concept. As with the other texts, this one appears to be intended to be used in a survey course and provides a generalized overview of HBSE concepts as a foundation for further study but does not delve into any specific topic in depth.

And, finally, the most recent textbook in the field surveyed by the authors is Anissa Taun Rogers' Human behavior in the social environment (2006). Although the term "culturally competent" does not appear in either the table of contents or the index, the text uses it in a table (Table 4.1) displaying various theories that are useful in social work practice. Even though the term is not specifically defined in the table, it indicates that the "theory of culturalism" helps social workers to be more culturally competent in practice. The text includes a section concerning cultural perspectives and social work and begins by defining terms such as multiculturalism and cultural pluralism.

\section{THEORY}

A central question that these education and practice mandates raise is how to assess the degree to which cultural competence has been met. When considering measurability or the accountability of organizations or individuals, a place to begin is to determine the theoretical nature of cultural competence (Kleinman and Benson, 2006; William, 2006). Is cultural competence theory or not? Whether it is or not has significance for measurability and accountability. To qualify as a theory, certain criteria must be met (see Table 2). A theory can be tested. One is able to empirically observe the phenomenon in question. The observation is replicable and the outcome reliable. If it does not meet standard criteria for a theory, then it should be considered to be a perspective. Meeting the criteria of a perspective allows for measurements of various components or aspects of the perspective.

\begin{tabular}{|l|l|}
\hline Table 2. & \\
\hline $\begin{array}{l}\text { Criteria or components for useful theory } \\
\text { (Babbie \& Rubin, 2005) }\end{array}$ & Cultural Competence \\
\hline $\begin{array}{l}\text { Observations: what we experience in the real } \\
\text { world that helps us build a theory or verify } \\
\text { whether it is correct }\end{array}$ & $\begin{array}{l}\text { what may be observed as culturally } \\
\text { competent is given to value judgments }\end{array}$ \\
\hline $\begin{array}{l}\text { Empirical support: when our observations are } \\
\text { consistent with what we would expect to } \\
\text { experience if a theory is correct }\end{array}$ & $\begin{array}{l}\text { cultural competence does not lend } \\
\text { itself to prediction or measurement }\end{array}$ \\
\hline $\begin{array}{l}\text { Attributes: concepts that make up a variable } \\
\text { (characteristics or qualities that describe) }\end{array}$ & $\begin{array}{l}\text { cultural competence lacks discernable } \\
\text { or agreed upon attributes }\end{array}$ \\
\hline $\begin{array}{l}\text { Hypothesis: something that ought to be } \\
\text { observed in the real world if a theory is correct }\end{array}$ & $\begin{array}{l}\text { cultural competence does not predict } \\
\text { behavior }\end{array}$ \\
\hline $\begin{array}{l}\text { Variables: the things that hypotheses predict } \\
\text { that hold relationships to one another } \\
\text { (independent \& dependent variables); logical } \\
\text { groupings of attributes }\end{array}$ & $\begin{array}{l}\text { cultural competence lacks a dynamic } \\
\text { relationship among variables }\end{array}$ \\
\hline
\end{tabular}


Theories are social constructions of what we think we know of reality. Epistemology is the study of knowing, and epistemologies are ways of knowing. Research based upon the scientific method is one approach to knowing. In social science, the scientific method remains the dominant approach to knowing or knowledge development. The recent debate between positivist and post-modernists notwithstanding, the building blocks of knowledge within the social sciences utilizing scientific method remain to be theories, constructs, models, paradigms and perspectives. A theory is the primary tool in the knowledge-building process. Theories are supposed to be testable, measurable, and constructed of logically-linked concepts and principles. Or, in Babbie's own words, "The credibility of a theory will depend on the extent to which: (1) our observations empirically support it, and (2) its components are systematically organized in a logical fashion that helps us better understand the world," (Babbie \& Rubin, 2005, p. 46.)

\section{DISCUSSION}

When considering the concept against the criteria for a theory, cultural competence does not meet the criteria for a stand-alone theory. It seems rather to be a perspective based upon a number of supportive social theories (such as socialization, theories of power, and theories about diversity) and values (such as equity and social justice). That it lacks the rigor of true theory need not diminish the value of the concept as a guide for social work education and practice. As a perspective, cultural competence can be viewed as a social construct that takes into account such factors as culture, politics, and history to help form a professional judgment. The inclusion of the variable of culture into the practice and education process is both a simple matter and a complex undertaking. It is, nonetheless, the basic element of cultural competence.

\section{SYSTEMS THEORY}

Cultural competence seems to have developed conceptually much like systems theory. Systems theory was introduced in 1927 by Ludvick Von Bertalanffy in his search for a unifying theory for the science of biology (VonBertalanffy, 1975.) When Gordon Hearn applied systems theory to social work, he pointed out that it was less a theory than a perspective and should be appreciated as such (Hearn, 1958.) Accordingly:

Life process is neither determined nor random. Prior life processes shape the probability of future events .... Prior life process shapes the probable range of future patterns of interaction. Stochastic process refers to the flow of human interactions subject to continual change, within a range of probability of future process (Hearn, 1976, p. 15-16.).

Similarly, the cross-cultural and pluralistic perspective in social work, referred to over 30 years ago, implies a conscious effort to break loose from the tendency to see social work practice exclusively in terms of one culture, class, or nation. It is in part an ongoing process of adding new dimensions and testing of values, 
assumptions, knowledge and skills. It is a freeing from the limited culture-bound view of man and society (Sanders, 1974, p. 47.).

The usefulness of systems "theory" in social work cannot be denied. It can be seen as the forerunner of such contemporary social work models as strength-based perspectives or ecological perspectives.

Similarly, cultural competence may best be thought of as a social construct composed of a number of concepts and principles, some of which might qualify as theories and others not (see Table 3). An example of contributing concepts is empowerment which for most authors seems to be a cornerstone of cultural competence. Empowerment was initially introduced to the cultural competence discussion by Barbara Solomon in 1978, and, more recently, it has been refined as a cultural competence concept in the writings of Lorraine Guttierez (Gutierrez, Zuniga, \& Lum, 2005). As a whole then, cultural competence best fits the definition of a perspective, i.e., a way of looking at things.

\section{Table 3. Components of a social perspective for culture/economy/political systems.} Farley (2005), also see Gordon Hearn, Systems Theory (1969)

Sociological Perspective: A way of looking at a question or problem. A perspective has three components:

1. An approach to a topic that helps to determine the kinds of questions that are asked about the topic.

\section{Cultural Competence as a Perspective}

Cultural competence as an approach to social work helps the profession to ask critical questions at the individual and environmental levels.

2. A theory or set of theories describing what is/are believed to be the realities of While not a theory in and of itself, cultural competence contains within its the topic.

3. Stated or unstated values concerning potentially-controversial issues related to the topic conceptualization a number of theories. Values of diversity and social justice are evident in any conceptualization of cultural competence.

\section{CONSEQUENCES}

The lack of intellectual consistency by which the concept of cultural competence has been presented leaves it open to criticism as a political ideology as is occurring with a number of critics [Lee \& Farrell, 2006; McElroy (ND)]. A spate of articles began to appear in the Chronicle of Higher Education in December of 2005 and continued until as recently as October 2006 (Wasley, 2006) describing a movement supported by the National Association of Scholars and the Foundation for Individual Rights in Education (FIRE) to question the accreditation standards in social work and in education that required curriculum which promoted social justice and diversity (Chronicle of Higher 
Education, 2006; Powers, 2006). The concerns were that these terms were being used to press a (liberal) political ideology on students of social work and education. The group of critics went so far as to threaten a law suit based upon the denial of civil rights of a student. An article in the October 2006 the Chronicle reported that the National Association of Teacher Education had withdrawn the "offensive language" referring to social justice from its accreditation requirements (Chronicle of Higher Education, 2006). This backlash against cultural competence and the multiculturalism it represents is being seen globally as in anti-immigrant protests throughout Europe. A cultural-competence perspective would appreciate in these cases that cultural competence may be different within societies just as the elements of democracy may be different in the mid-East or in the rules of the free market different in China.

The failure of cultural competence to meet the standards/criteria of theory, notwithstanding, means students, practitioners, organizations, and institutions still should be held accountable for being culturally sensitive and to promote diversity and social justice. If cultural competence calls for the inclusion of the variable of culture into the social work process, then it is fundamental to effective practice.

Not to dilute the attention needed to address racism and discrimination but recognizing the universal value of cultural competence for social work would move our practice expectations from a specialized application of social work to a normative one. Consider, for example, a study by Boyle and Springer (2001) in which four measures of cultural competency in the social work profession are analyzed and are found to measure global constructs that may not be applicable to specific cultures. And, as we can assess good social work, so can we assess cultural competence through models of evidencedbased practice and client outcomes. Perhaps it is time for a new term that would incorporate the perspectives of cultural competence and good social work (Koehn \& Swick, 2006). Civic/civil competence might achieve such a conceptual task. The notion of civic competence infers a move beyond a focus upon the variable of culture only and beyond the implicit emphasis on ethnicity or race (Klienman \& Benson, 2006; Williams 2006).

Moving our attention from cultural competence to civic competence would place cultural competence within the realm of the assessment of concepts and principles of good social work such as are already applied to practice activities like trust building, therapeutic relationships, clinical observations, and assessment skills. On a macro scale, civic competence should represent a standard of assessment and analysis similar to that applied to issues of social justice. It is a value framework that incorporates culture in our critical analyses of power differentials present, for example, in gender and racial disparities as are found in poverty, discrimination, and oppressions. Acknowledging cultural competence as a value-based way of looking at things would disarm critics who hold the concept to the light of empirical analysis. Viewing cultural competence as a perspective and not a theory would also help practitioners to focus upon the specific variables of culture much as social workers focus upon the variables of psychology within an environmental context. This broader conceptualization recognizes the lack of conceptual specificity in definitions of cultural competence and the resulting difficulty to lend itself 
to outcome assessments. This vagueness of the concept also exposes the concept of cultural competence to intellectual and political criticism. In response to these concerns, the authors suggest that cultural competence may be considered to be simply good social work and, as such, can be assessed using the same tools used for good evidence-based practice. Such a practice would allow advances necessary to develop globally-applicable models of social work intervention.

\section{References}

Adams, Damon. (April 25, 2005) Cultural competency now law in New Jersey, AMNews, Amednews.com. http://ama-assn.org/amednews.

Ashford, Jose, LeCroy, Craig \& Lortie, Kathy. (2006). Human Behavior in the Social Environment: A multidimensional perspective ( $3^{\text {rd }}$ ed.). Belmont, CA: Wadsworth/ Thomson Learning.

Babbie, Earl, \& Rubin, Allen. (2005). Research methods for social work (5 ${ }^{\text {th }}$ ed.). Belmont, CA: Brooks/Cole.

Bigby, Judyann. (2003). Cross-cultural medicine. Philadelphia, PA: American College of Physicians.

Blue, Amy V., Thiedke, Carolyn, Chessman, Alexander W., Kern, Donna H., and Keller, Albert. (2005). Applying theory to assess cultural competency. Retrieved July10, 2006, from Med Educ. http://med-ed-online.org.

Boyle, David. P., \& Springer, Alyson. (2001). Toward a cultural competence measure for social work with specific populations. Journal of Ethnic \& Cultural Diversity in Social Work, 9(3/4), $53-71$.

Campinha-Bacote, Josepha. (1994). The process of cultural competence in health care: A culturally competent model of care. Wyoming, OH: Transcultural CARE Associates.

Chronicle of Higher Education. (2006). News blog: Social-work accreditor assailed in 3 letters to Health and Human Services Department. October 25. Retrieved January 22, 2007 from http://chronicle.com/news/article/1182/social-work-accreditorassailed-in-3-letters-to-Health-and-Human-Services.

Council on Social Work Education (CSWE). (2006). Council on Social Work Education, Commission on Accreditation Handbook on Accreditation Standards and Procedures. ( $5^{\text {th }}$ ed.). Arlington, VA: CSWE.

Cross, Terry., Bazron, Barbara, Dennis, Karl, \& Issacs, Mareasa. (1989). Towards a culturally competent system of care. Vol. 1. Washington, DC: Georgetown University Child Development Center.

Davis, P., \& Donald, B. (1997). Multicultural counseling competencies: Assessment, evaluation, education and training, and supervision. Thousand Oaks, CA, Sage Publications.

Farley, John. (2005). Minority-majority relations. (5 ${ }^{\text {th }}$ ed.). Upper Saddle River, NJ: Prentice Hall.

Gallegos, Joseph. (1982). The ethnic competence model for social work education. In B. W. White (Ed.), Color in a white society. Silver Spring, MD: National Association of Social Workers. 
Green, James. (1982). Cultural awareness in the human services. Englewood Cliffs, NJ: Prentice-Hall, Inc.

Green, James. (1995). Cultural awareness in the human services a multi-ethnic approach. Needham Heights, MA: Allyn and Bacon.

Gutierrez, Lorraine, Zuniga, Maria., \& Lum, Doman. (Eds.) (2005). Education for multicultural social work practice: Critical viewpoints and future directions. Alexandria, VA: Council on Social Work Education.

Hage, Jerald. (1972). Techniques and problems of theory construction in sociology. New York, NY: Wiley-Interscience.

Hearn, Gordon. (1958). Theory building in social work. Toronto, Canada: University of Toronto Press.

Hearn, Gordon. (1969). The general systems approach: Contributions toward a holistic conception of social work. New York, NY: Council on Social Work Education.

Hearn, Gordon. (1976, March). General systems perspectives and social work education. Paper presented at the Annual Program Meeting of the Council on Social Work Education, Philadelphia, PA.

Hutchinson, Elizabeth. (1999). Dimensions of human behavior: Person and environment. The changing life course. Thousand Oaks, CA: Sage Publications.

Inside Higher Education. (May 2005). Outrage over diversity plan. Retrieved January 11, 2007 from http://insidehighered.com/layout/set/print/news/2005/05/31/oregon.

Inside Higher Education. (June 2006). Social justice powers. From http://goacta.org/press/articles/1HE6-6006-html.

Klienman, Arthur \& Benson, Peter. (October 24, 2006). Anthropology in the clinic: The problem of cultural competency and how to fix it. PLoS Med 3(10): e294. DOI: 10:1371/journal.pmed.0030294.

Koehn, Peter, \& Swick, Herbert. (2006). Medical education for a changing world: Moving beyond cultural competence into transnational competence. Academic Medicine, 81(6), 548-556.

Longres, John. (2000). Human behavior in the social environment. Itasca, IL: F.E. Peacock Publishers, Inc.

Lum, Doman. (1999). Culturally-competent practice: A framework for growth and action. Pacific Grove, CA: Brooks/Cole Publishing Company.

Lum, Doman. (Ed.). (2005). Cultural competence, practice stages, and client systems. Belmont, CA: Thomson Brooks/Cole.

Multnomah County. (2005). The policy framework for cultural competency. Office of the Chair, Multnomah County, OR.

National Association of Social Workers. (June 23, 2001). NASW standards for cultural competence in social work practice. Washington, DC: NASW National Committee on Racial and Ethnic Diversity, Approved by the NASW Board of Directors.

Powers, Elia. (2006). A spirited disposition debate, foundation for individual rights in education [Electronic version]. Inside Higher Education. Philadelphia, PA. 6(6).

Pedersen, P. \& Marsell, A. (1982). The ethical crisis for cross cultural counseling and therapy. Professional Psychology, August, 13(4), 492-500. 
Purnell, Larry, \& Paulanka, B. J. (2003). Purnell's model for cultural competence. In: L. D. Purnell \& B. J. Paulanka (Eds.). Transcultural health care: A Culturallycompetent Approach. Philadelphia, PA: F.A. Davis Company.

Pyles, Loretta \& Kyung, Mee Kim. (2006) A multilevel approach to cultural competence: A study of the community response to underserved domestic violence victims. Families in Society: The Journal of Contemporary Social Science. 87(2), 221-229.

Rogers, Anissa. (2006) Human behavior in the social environment. New York, NY: McGraw Hill Higher Education.

Sanders, Daniel. (1974). Educating social workers for the role of effective change agents in a multicultural pluralistic society. Journal of Education for Social Work. $\mathrm{X}(2), 86-91$.

Solomon, Barbara. (1977). Black empowerment: Social work in oppressed communities. Irvington, NY: Columbia University Press.

Sue, D. W., \& Sue, D. (1999). Racial/cultural identity development: Therapeutic implications. In D. W. Sue and D. Sue, Counseling the culturally different: Theory and practice (3rd ed.) (pp. 121-142). New York: John Wiley and Sons.

Sue, D.W., Bernier, J.B., Durran, M., Feinberg, L., Pedersen, P., Smith, E., \& VasquezNuttall, E. (1982). Position paper: Cross-cultural counseling competencies. The Counseling Psychologist. 10 (2), 45-52.

Suh, Eunyoung Eunice (2004) The model of cultural competence through an evolutionary concept analysis. Journal of Transcultural Nursing._(15) 2, 93-102.

Sutton, Marla. (2000). Cultural competence: It's not just political correctness. It's good medicine. [Electronic version.] American Academy of Family Physicians. http://www.aafp.org/fpm/20001000/58cult.html.

Von Bertalanffy, Ludwig. (1975). Perspectives on general systems theory, scientificphilosophical studies. E. Taschdjian (ed.) New York, NY: George Brazillier.

Wasley, Paula. (June 2006). Accreditor of education schools drops controversial 'social justice' standard for teacher candidates. Washington, DC: Chronicle of Higher Education. 52(41), A13.

Weaver, Hilary N. (2005) Explorations in cultural competence: Journeys to the four directions. Belmont, CA: Thomson Brook/Cole.

Williams, Charmaine C. (2006). The epistemology of cultural competence. Families in society: The Journal of Contemporary Social Science. 87(2), 209-220.

Winkelman, Michael. (2005). Cultural awareness, sensitivity, \& competence. Peosta, IA: Eddie Bowers Publishing Co., Inc.

Wu, E, \& Martinez M. (2006). Taking cultural competency from theory to action. The Commonwealth Fund.

Zastrow, Charles \& Kirst-Ashman, Karen. (2006). Understanding Human Behavior in the Social Environment (6 ${ }^{\text {th }}$ ed.). Belmont, DC: Brooks/Cole.

\section{Author's note:}

Address correspondence to: Joseph S. Gallegos, Ph.D., Director, Social Work Program, University of Portland. 5000 N. Willamette Blvd., Portland, OR 97203. E-mail: gallegos@up.edu. 